\title{
O Ideário de Escola na Ótica dos Docentes: Pura Subjetividade ou Padrões Estruturados de Cognição nos Cursos de Administração?
}

\section{The Ideality of the School in the View of Faculty: Pure Subjectivity or Structured Cognition Patterns in the Business Administration Programs?}

Mestrando em Administração do CEPPAD/UFPR, Curitiba/PR, Brasil.

Antonio João Hocayen-da-Silva Mestrando em Administração do CEPPAD/UFPR, Curitiba/PR, Brasil.

Marcos de Castro Mestrando em Administração do CEPPAD/UFPR. Professor da Unicentro, Guarapuava/PR, Brasil.

*Endereço: Rua Victor Hugo, 131, Guairá, Curitiba/PR, 81010-130. E-mail: crmaciel.adm@gmail.com 


\section{ResUMo}

No presente estudo buscou-se identificar, a partir da percepção de docentes, quais são os fatores fundamentais para a construção e manutenção da qualidade do Ensino Superior Privado nos Cursos de Administração de Curitiba, PR. A Perspectiva Institucional de Análise e a Abordagem Cognitiva dos Estudos Organizacionais figuraram como referencial para tal investigação. Após entrevistas em profundidade com alguns docentes foi possível o desenvolvimento de um questionário estruturado para a realização de um survey. Na fase quantitativa da pesquisa a amostragem por adesão resultou em 214 questionários preenchidos por professores de 24 IES da cidade. Os achados da pesquisa apontam evidências da presença de três padrões estruturados de cognição entre os pesquisados: (1) Docente Com Bom Relacionamento e Presença em Sala de Aula; (2) Docente Bem Qualificado; e (3) Docente Com Maior Experiência Profissional. O artigo se encerra discutindo os padrões cognitivos dos três grupos identificados e levanta possíveis questionamentos quanto às implicações desses padrões na qualidade do ensino nos cursos de administração. Em complemento, são levantadas sugestões de futuras pesquisas acerca da relação entre padrões estruturados de cognição, redes sociais e a lógica de mudança e estabilidade, a partir da noção de contradições institucionais.

Palavras-chave: cognição estruturada; ideário de escola; escolas de administração.

\section{ABSTRACT}

The present study aimed at identifying, under the professors' perception, the main factors for both constructing and maintaining quality in the business administration private schools throughout Curitiba-PR. The institutional perspective of analysis and the cognitive approach of organizational studies were the referential framework for such investigation. After interviewing a few members of the faculty it was possible to develop a structured questionnaire. At the quantifying stage of the research sampling has resulted 214 questionnaires properly filled by professors of 24 higher education institutions. The results show evidence of the presence of three structured patterns of cognition among surveyed professors: (1) Professors with good relationships and classroom participation; (2) Well qualified faculty; and (3) Faculty with a higher professional experience. When the article finishes it discusses cognitive patterns among three fully identified groups and it raises possible questions as to the implications of these patterns in the quality of business administration courses. In addition future research suggestions are raised on the connection between structured patterns of cognition, social networks as well as the logic of changes and stability from the notion of institutional contradictions.

Key words: structured cognition; ideality of the school; business school. 


\section{INTRODUÇÃO}

Ainda que relativamente recente, a preocupação com a qualidade do ensino superior em administração e com a formação do administrador tem sido uma constante nas décadas que se seguiram à instituição e desenvolvimento do curso no Brasil. Atrelado ao desenvolvimento econômico e social do próprio país nos últimos cinquienta anos, assim como a maioria dos cursos de graduação, o curso de administração experimentou um crescimento mais ou menos cadenciado até uma década atrás.

A partir de meados dos anos 90, esse cenário apresentou crescimento de tendências exponenciais, quando comparado aos anos anteriores (Instituto Nacional de Estudos e Pesquisas Educacionais Anísio Teixeira [INEP], 2006). Entretanto, se o crescimento da oferta dos cursos de administração é inquestionável, não é possível dizer o mesmo em relação à qualidade do ensino desses cursos, não que isso tenha sido discutido somente nos últimos dez anos. O problema com a qualidade do ensino em administração não é de natureza contingencial; ele tende a ser estrutural, em razão, talvez, da falta de prestígio e identidade do curso, na sua implantação no país. Em adição, o ensino da administração, enquanto negócio, e a conseqüiente e acentuada variabilidade indesejada na qualidade não é característica da expansão de um mercado explorado só agora; o oportunismo inconsequiente das empresas de ensino permeia a atualidade, datando desde os anos 60 (Motta, 1983).

Nesse sentido, ao discutir a qualidade do ensino, deve-se de antemão questionar: qualidade para quem? Buscar a resposta sobre o que é qualidade do ensino com alunos, escolas, órgãos regulamentadores e docentes pode trazer um universo de respostas incongruentes. Considerando ainda que existem subgrupos no interior dessas constituências (i.e., elementos ambientais que exercem o papel de audiência institucional), com visões de mundo e objetivos diferenciados, a resposta torna-se mais complexa. Daí decorre a preocupação que permeia todo esse artigo. A posição do que seja qualidade, ou os critérios para se julgar a qualidade do ensino em administração é suscetível de ser inferida a partir de pesquisas com alunos; da observação do discurso das escolas de administração; ou ainda da análise das regras e normas dos órgãos regulamentadores do ensino superior. Por outro lado, aquilo que se julga qualidade na ótica dos docentes não tem sido objeto de análise mais ampla e sistematizada.

No plano empírico parece óbvia a constatação de que existem perfis de professores que se aglutinam em grupos que, por apresentarem percepções, 
crenças e valores, e interesses compatíveis, acabam por interpretar, de forma bastante homogênea, a realidade do que seja um ensino de qualidade em nível superior, mas em alguma medida de forma discrepante dos docentes que fazem parte de outros grupos (Festinalli, 2005; Machado-da-Silva, 2003; Morosini, 1997).

A maior preocupação que decorre de tal assertiva é a de que as ações desses atores sociais são teoricamente condizentes com a sua forma de interpretar a realidade. As práticas de ensino e a postura do docente em sala de aula são em certa medida condicionadas pelo seu modo de ver o mundo, de interpretar aquilo que é bom ou não para o desenvolvimento do seu trabalho e para a qualidade do ensino. Não é demais esclarecer que a qualidade do ensino em administração, na dependência da interpretação desses diferentes grupos, pode tomar um curso bem definido, desde que haja suficiente consonância entre eles. Por outro lado, pode tomar diversos rumos e chegar a lugar nenhum, dada a falta de congruência entre os diferentes grupos no que tange aos esforços de se assegurar as práticas e metodologias que efetivamente colaborem com a construção e manutenção da qualidade do ensino (Machado-da-Silva, 2003; Morosini, 1997; Vasconcelos, 1996).

Decorrente dessa problemática, que envolve o binômio interpretação-ação dos docentes do curso de administração, tomou-se como pano de fundo a Teoria Institucional e a Abordagem Cognitiva dos estudos organizacionais para a observação dos fatores fundamentais da qualidade do ensino em administração em instituições privadas. Tais perspectivas de análise podem colaborar substancialmente para o entendimento dos padrões estruturados, ou institucionalizados de cognição dos atores pesquisados, a partir da noção dos mecanismos isomórficos, legitimidade e ambiente institucional (Bartunek, 1984; Daft \& Weick, 1984; DiMaggio \& Powell, 1983; Greenwood \& Hinings, 1993, 1996; Machado-da-Silva, Fonseca, \& Crubellate, 2005; Meyer \& Rowan, 1977; Powell \& DiMaggio, 1991; Scott, 1992, 1994, 1995, 2001).

O entendimento do que se refere à cognição estruturada se assenta na noção de padrões institucionalizados de cognição; grupos de atores sociais que são diferenciados de outros grupos, mas internamente homogêneos no que tange a sua forma de ver o mundo, ou em seus esquemas interpretativos, que estão invariavelmente em contínua e mútua interação com estruturas institucionais que operam em variados níveis do contexto ambiental. Essa noção de padrões estruturados de cognição vem sendo inicialmente explorada nas áreas de sociologia e estratégia, a partir do enfoque da Teoria Institucional e da Teoria da Estruturação de Anthony Giddens (1989).

Quanto à sua estrutura, o artigo inicia por essa breve introdução ao objetivo de 
pesquisa, que é identificar, a partir dos padrões de percepção de docentes, quais são os fatores fundamentais para a construção e manutenção da qualidade do Ensino Superior Privado nos Cursos de Administração na cidade de Curitiba, PR. Na seqüência apresentam-se o referencial teórico, a metodologia da pesquisa, a análise dos dados, a discussão dos resultados e as considerações finais, envolvendo também as limitações do estudo e sugestões para futuras pesquisas.

\section{Teoria Institucional e Interpretação da Realidade Social}

A constituição do que se toma sob o rótulo de Teoria Institucional é observada por Machado-da-Silva e Gonçalves (1999, p. 220), como:

(...) o resultado da convergência de influência de corpos teóricos originários principalmente da ciência política, da sociologia e da economia, que buscam incorporar em suas proposições a idéia de instituições e de padrões de comportamento, de normas e de valores, de crenças e de pressupostos, em que se encontram imersos indivíduos, grupos e organizações.

De acordo com os institucionalistas, crenças e valores cristalizados e racionalizados na sociedade orientam a ação dos atores sociais. Ao serem atendidas as exigências desses padrões, os atores sociais são premiados com a legitimidade para suas atividades e, dessa forma, garantem sua aceitação e orientam suas atividades e práticas ao isomorfismo (DiMaggio \& Powell, 1983; Meyer \& Rowan, 1977; Scott, 2001).

$\mathrm{Na}$ caracterização da perspectiva institucional, alguns autores, como Abell (1995), a apresentam como perspectiva de contraposição ao modelo de ator racional, o que na verdade não ocorre. O que acontece na Teoria Institucional é a incorporação de valores ao modelo de ator racional, porém dentro de novas dimensões, concebendo o ator social como portador de racionalidade limitada (Simon, 1965).

Em sua ênfase fenomenológica, a Teoria Institucional reconhece que símbolos não existem apenas como crenças internalizadas (subjetivas), mas também como estruturas externas ao indivíduo (Scott, 1994, 2001). As crenças não são meramente subjetivas e internas, mas em algum grau intersubjetivamente compartilhadas, adquirindo status de real e objetivo por meio do processo de institucionalização.

Dentro dessa lógica, o conhecimento da vida cotidiana resulta do processo de formação de hábitos, sob condição de reciprocidade, que é verificada no estoque 
de conhecimentos do indivíduo como um corpo de rotinas constituídas de atividades tomadas por ele como certas, taken for granted. Esse processo é separado em três momentos: exteriorização, objetivação e interiorização. Na exteriorização se dá a construção social da realidade com origem nas atividades cotidianas e sua posterior habitualização. Na objetivação ocorre a institucionalização do que se tornou habitual, para que, em decorrência do que foi institucionalizado, o indivíduo possa obter uma significação de mundo. Nessa última fase, o homem é produto social, e o mundo social objetivado é reintroduzido na consciência do ator no curso da socialização. Cada um desses movimentos dialéticos de exteriorização, objetivação e interiorização, correspondem a uma caracterização de mundo, respectivamente: "A sociedade é um produto humano. A sociedade é uma realidade objetiva. O homem é um produto social" (Berger \& Luckmann, 1998, p. 87).

O conhecimento intersubjetivamente compartilhado, decorrente do processo de institucionalização, representa um processo contínuo de reconstrução e construção de velhos e novos padrões que gozem de maior ou menor conformidade com os padrões institucionais vigentes em variados níveis e esferas do ambiente institucional (Scott, 1995, 2001). Como consequiência do processo de adoção de práticas similares de um ator social por outros, em busca de legitimidade, emerge o assemelhamento das atividades e práticas sociais (DiMaggio \& Powell, 1983; Scott, 1994, 2001; Suchman, 1995).

Com o foco nas organizações, DiMaggio e Powell (1983) defendem que esse processo de homogeneização decorre de três mecanismos institucionais isomórficos: (i) mecanismo isomórfico coercitivo; (ii) mecanismo isomórfico mimético; e (iii) mecanismo isomórfico normativo.

O mecanismo isomórfico coercitivo pode resultar tanto de pressões formais como informais, de maneira que determinadas organizações são submetidas a outras que apresentam posição de maior poder na relação de dependência. O mecanismo isomórfico mimético decorre da imitação. A incerteza é tida como principal fonte de imitação do que foi considerado por uma organização como sucesso ou fonte de legitimidade de outra. Sob a influência desse mecanismo, tende a ocorrer uma modelagem das organizações com base em outras organizações, em face de objetivos ambíguos ou incertezas simbólicas criadas pelo ambiente. A modelagem em resposta à incerteza poderá ser até mesmo não consciente e sem desejo de imitação, como freqüentemente acontece; por exemplo, com transferência de pessoal ou turnover ou, ainda, pelo emprego de soluções formuladas por firmas de consultoria. Essa imitação é considerada apenas uma conveniente fonte de práticas a serem "tomadas de empréstimo" de outras organizações (DiMaggio \& Powell, 1983). Por sua vez, o mecanismo 
isomórfico normativo tem sua origem primariamente na profissionalização, interpretada por DiMaggio e Powell (1983, p. 152), como "a luta coletiva dos membros de uma ocupação para definir as condições e métodos de sua atividade [...] e para estabelecer uma base cognitiva e de legitimação para sua autonomia ocupacional".

É com o foco nesse último mecanismo institucional isomórfico que a presente investigação foi realizada. Entretanto cabe esclarecer que processos isomórficos institucionais e a busca por legitimidade não encerram os contornos das ações e práticas dos atores sociais na Teoria Institucional (Machado-daSilva, Fonseca, \& Fernandes, 1999; Machado-da-Silva \& Gonçalves, 1999). Há que considerar a possibilidade de variação nessas práticas e ações, em razão da variabilidade nas crenças e valores que estruturam os esquemas interpretativos. Seguindo a abordagem cognitiva dos estudos organizacionais os institucionalistas entendem os esquemas interpretativos como "os pressupostos resultantes da elaboração e arquivamento mental de percepções e objetos dispostos na realidade, que operam como quadros de referência, compartilhados e frequientemente implícitos, de eventos e comportamentos apresentados pelos agentes organizacionais em diversas situações" (Machadoda-Silva \& Fonseca, 1993, p. 151).

Em adição, esses esquemas interpretativos poderão estar voltados a diferentes contextos ambientais de referência: local, regional, nacional ou internacional (Machado-da-Silva et al., 1999). Como os apontamentos acima sugerem, os atores sociais (i.e., os docentes dos cursos de administração em exame) efetivamente interpretam a realidade social de forma diferenciada, subjetiva, mas em grande medida ainda de forma intersubjetivamente compartilhada (Berger \& Luckmann, 1998).

São essas interpretações intersubjetivamente compartilhadas que dão coerência às ações dos atores individuais. Entretanto, como já foi mencionado, essas interpretações sofrem variações; por isso acabam por não formar um sistema monolítico de interpretação da realidade social. São essas variações que são suscetíveis de identificação em função de padrões estruturados de cognição, que se assentam na noção de cognição institucionalizada (Machado-da-Silva et al., 2005; Selznick, 1996) em diferentes grupos de atores sociais que mantêm internamente uma mais alta convergência de crenças e valores e, portanto, semelhança também na forma de interpretar a realidade e agir sobre ela. Em específico, no que se refere aos docentes do curso de administração, faz-se necessário evidenciar esses padrões estruturados de cognição para conhecer quem efetivamente ensina a administração e é responsável pela formação dos administradores. 
A partir dessas idéias principais, a pesquisa foi operacionalizada por meio da realização de um survey (Babbie, 1998, 2001; Kerlinger, 2003). Os principais contornos metodológicos constam na seção seguinte do artigo.

\section{Metodologia}

O estudo consistiu em uma pesquisa de natureza exploratória que fez uso de um survey para o cumprimento do objetivo de descrição (Babbie, 1998, 2001; Kerlinger, 2003). A pesquisa descritiva visa efetuar a descrição de processos, mecanismos e relacionamentos existentes na realidade do fenômeno estudado, utilizando para tanto um conjunto de categorias ou tipos variados de classificações (Neuman, 1997). Essa metodologia de pesquisa é recomendada, quando se tem a intenção de descrever um número maior de observações, tanto em pesquisas conclusivas (descritivas ou explicativas) quanto em surveys piloto. Ainda que seja uma limitação do estudo levantar, por meio de questionários, a importância ou a valorização que os docentes atribuem aos critérios pesquisados, o survey se mostrou a alternativa mais viável, dada a amplitude e cobertura da pesquisa. Ademais, diversas pesquisas têm sido realizadas de forma quantitativa para o levantamento de construtos relacionados às crenças e valores nas organizações (e.g., Cochia \& Machado-da-Silva, 2004; Guarido \& Machado-da-Silva, 2001; Oliveira \& Machado-da-Silva, 2001; Swaminathan, 1995; Westphal, Gulati, \& Shortell, 1997).

O processo geral da pesquisa seguiu inicialmente uma fase qualitativa de investigação com cinco docentes, e uma segunda fase quantitativa. Na primeira fase da pesquisa, as entrevistas individuais tiveram resultados bastante redundantes. Os professores pesquisados faziam frequientes referências à estrutura, às condições de trabalho proporcionadas pelas IES e às características profissionais que melhor retratam o perfil desejado de docente. Após a análise das entrevistas semi-estruturadas, foi desenvolvido o instrumento de coleta de dados para o levantamento do grau de valorização das características das IES e do perfil de docente.

Os indicadores (variáveis) que compuseram o construto Adequação das IES privadas foram os seguintes: (1) apoio financeiro à qualificação do docente; (2) adequação dos horários do docente para a sua qualificação; (3) apoio financeiro para a participação em eventos; (4) apoio para atividades extracurriculares; (5) incentivo moral à publicação; (6) incentivo moral para a realização de pesquisas; (7) equipamentos de apoio às aulas na instituição; (8) instalações físicas; e (9) biblioteca. 
Os indicadores do Perfil de Docente formaram um conjunto de 22 variáveis: (1) curso de doutorado; (2) pontuação no Qualis; (3) possuir currículo Lattes; (4) participação em grupos de pesquisa do CNPq; (5) curso de mestrado; (6) publicação de artigos científicos; (7) curso de pós-doutorado; (8) participação em congressos e seminários; (9) dedicação exclusiva do professor; (10) capacidade técnica para orientações; (11) capacidade para unir teoria e prática; (12) didática em sala de aula; (13) dedicação e entusiasmo do professor; (14) relacionamento com os alunos; (15) criatividade do professor; (16) leitura de periódicos específicos da área; (17) contato com outros acadêmicos; (18) relacionamento com a coordenação do curso; (19) interesse por orientações; (20) relacionamento com outros professores; (21) ocupação extra-acadêmica; e (22) experiência profissional anterior extra-acadêmica.

Os critérios de Adequação das IES e os critérios relacionados aos Valores Profissionais, considerando aquilo que é valorizado pelo docente e que ele acredita ser essencial para a qualidade do ensino, foram mensurados a partir da sua importância com uma escala intervalar de 5 pontos com os indicadores avaliados todos na mesma direção (i.e., sem escala invertida). Outras variáveis nominais foram insertas no questionário para o levantamento do gênero e qualificação dos pesquisados.

Na seqüência ocorreu o pré-teste do instrumento de coleta de dados, a aplicação dos questionários, codificação, tabulação e a análise dos dados. Na fase do préteste foram pesquisados oito docentes da área de administração em instituições privadas de ensino superior em Curitiba. Estes docentes foram selecionados com base nos critérios estabelecidos por Marconi e Lakatos (1990) e Vergara (1998): (i) aspectos de acessibilidade (seleção de elementos pela facilidade de acesso a eles); e (ii) tipicidade (seleção de elementos representativos na população). Os questionários foram aplicados individualmente, com o acompanhamento dos pesquisadores, ocasião em que os respondentes foram instruídos a identificar as questões que levantassem dúvidas no seu entendimento.

Quanto ao universo pesquisado, foi verificado o número total de IES privadas junto ao Conselho Regional de Administração, CRA, em Curitiba/PR, com a intenção de identificar as instituições da capital paranaense que oferecem cursos de administração. A partir da coleta dessas informações, identificou-se que o universo da pesquisa seria formado por 24 instituições. Em face desse número de IES, os pesquisadores optaram por realizar o estudo que envolvesse o universo total de instituições localizadas em Curitiba, mas sem o comprometimento com a generalização dos resultados. A amostra final foi composta pelos docentes que responderam aos questionários, o que caracteriza a composição final como amostra por adesão. 
Foram distribuídos 934 questionários aos professores dos cursos de administração de 24 IES privadas de Curitiba, com o objetivo de levantar informações quanto aos construtos a serem observados no estudo. A amostra final consistiu em 214 questionários válidos. A fase posterior da pesquisa envolveu a análise dos dados com o auxílio do software estatístico SPSS 13 for Windows.

\section{Caracterização da Amostra}

Com relação à amostra, dos 214 respondentes foram observados 208 questionários sem missing values na questão sexo do entrevistado ou nível de formação. Desses 208 docentes 70,70\% são do sexo masculino e $29,30 \%$ do sexo feminino. Do grupo dos homens 29,30\% são especialistas, $52,40 \%$ mestres e 18,30\% doutores. Do grupo das mulheres $18,05 \%$ são especialistas, $63,90 \%$ mestras e 18,05\% doutoras. A média de idade dos pesquisados é de 42 anos com um desvio padrão de 9,5 anos. Os mestrandos foram incluídos na categoria mestres e os doutorandos na categoria doutores.

\section{AnÁlise dos Dados}

A análise dos dados teve início pela verificação de missing values, presença de outliers, normalidade e linearidade das variáveis intervalares. Esses procedimentos foram seguidos para assegurar a não violação dos pressupostos da análise multivariada. Quanto aos missing values foi verificado que nenhuma das variáveis superou 5 valores faltantes $(0,02 \%)$. Na seqüência esses valores faltantes foram substituídos pelas médias das variáveis para que todos os casos fossem utilizados nas análises posteriores, sem comprometer outras análises estatísticas. Para a análise dos outliers foi verificada a Distância de Mahalanobis $\left(D^{2}\right)$. Esse procedimento indica a um nível de significância bastante conservador $(p$-value $<0,001)$ quais variáveis são atípicas, considerando sua posição em relação ao centro de todas as outras observações (Hair, Anderson, Tathan, \& Black, 1995). Os 3 casos de valores extremos foram extraídos da amostra.

Para o diagnóstico de normalidade das variáveis a análise gráfica não permitiu maiores conclusões. Posteriormente foi realizado o teste Kolmogorov-Smirnov, considerando um $p$-value $<0,005$, em que foi constatado que apenas 12 variáveis não apresentaram distribuição estatisticamente diferente da distribuição normal. Todavia os cálculos de curtose apresentaram índices entre $\pm 1,5$, enquanto a 
assimetria mostrou valores entre \pm 1 . Em face desses valores de curtose e assimetria, optou-se por empregar técnicas multivariadas de análise sem maiores restrições. Schumacker e Lomax (2004) afirmam que variáveis com índices de assimetria e curtose compreendidos entre esses valores se aproximam da distribuição normal e permitem a utilização de métodos estatísticos que pressuponham normalidade. No que concerne à linearidade, nem todas as variáveis se mostraram correlacionadas, o que ressaltou a necessidade de aplicação de uma análise fatorial.

A fim de identificar as dimensões subjacentes aos construtos, os dados foram submetidos à Análise Fatorial Exploratória de Componentes Principais. De acordo com Hair et al. (1995), a Análise Fatorial Exploratória [AFE] consiste em uma técnica estatística para a análise de padrões de complexas relações multidimensionais entre um número mais expressivo de variáveis. A utilização dessa técnica se justifica pela necessidade de condensar e reduzir grande número de variáveis a poucas dimensões ou fatores latentes de alguns construtos. Para se assegurar a adequação do emprego dessa técnica, buscou-se atentar para a razão casos-por-variável, evitando assim um superajustamento dos dados. $\mathrm{O}$ recomendado por Hair et al. (1995) é que se tenha um mínimo de 5 casos por variável. Esse critério foi respeitado nas duas análises fatoriais que se seguiram. O primeiro construto (Adequação das IES) foi formado por 9 variáveis para uma amostra total de 214 casos, o que resultou em 23 observações por variável. $\mathrm{O}$ segundo construto (Valores Profissionais dos Docentes) foi composto de 22 variáveis para as 214 observações. Portanto, na segunda análise fatorial, foi constatado um índice de 9 observações por variável.

Após o processo de validação fatorial das escalas, foi realizada ainda uma análise de confiabilidade das medidas. Para a observação da confiabilidade dos fatores identificados na Análise Fatorial, foi verificado o Alfa de Cronbach (Hair et al., 1995). Essa lógica de utilização da técnica de análise fatorial para validação das escalas e do cálculo do índice de consistência interna para indicação da confiabilidade das medidas é largamente explorada em trabalhos similares no exterior (e.g., Bartel \& Saavedra, 2000; Dukerich, Golden, \& Shortell, 2002; Farh, Earley, \& Lin, 1997; Polzer, Milton, \& Willian, 2002).

Na Análise Fatorial foi adotado o método de extração de componentes principais, seguida da definição do método de rotação ortogonal VARIMAX. Após a execução da técnica, alguns cuidados foram tomados para garantir a adequação do emprego da técnica. Para tanto, a Análise Fatorial foi seguida da verificação da matriz de correlação das variáveis, da medida de adequação da amostra (KMO) e do teste de esfericidade de Bartlett. 
O primeiro construto analisado foi a Adequação das IES para a qualidade do ensino na percepção dos docentes. Foram identificados dois fatores, Fator 1 Apoio Institucional e Fator 2 - Estrutura. Essa primeira análise apresentou um $\mathrm{KMO}=0,812$ e teste de esfericidade de Bartlett $=947,786$ com significância $=$ 0,000. Os fatores apresentaram, respectivamente, Alfas de Cronbach de 0,88 e 0,79 , considerados adequados para pesquisas de natureza exploratória. Os resultados constam na Tabela 1 .

\section{Tabela 1: Análise Fatorial Rotacionada para Importância da Adequação das IES}

\begin{tabular}{l|c|c}
\hline \multicolumn{1}{c|}{ Variáveis } & Fator 1 & Fator 2 \\
\hline Apoio financeiro à qualificação & 0,798 & \\
\hline Adequação de horários para qualificação & 0,774 & \\
\hline Apoio financeiro à participação em eventos & 0,781 & \\
\hline Apoio para atividades extracurriculares & 0,739 & \\
\hline Incentivo moral à publicação & 0,711 & 0,882 \\
\hline Incentivo moral à pesquisa & 0,722 & 0,876 \\
\hline Equipamentos de apoio & & 0,636 \\
\hline Instalações físicas & & $26,08 \%$ \\
\hline Biblioteca & & $65,98 \%$ \\
\hline Variância explicada & $39,90 \%$ & 0,786 \\
\hline Variância acumulada & $39,90 \%$ & \\
\hline Alfa de Cronbach & 0,881 & \\
\hline
\end{tabular}

Fonte: dados primários da pesquisa.

O segundo construto submetido aos procedimentos de validação e confiabilidade da escala foi o Perfil de Docente dos cursos de administração que abarcava os indicadores referentes às características do perfil profissional valorizado pelos pesquisados. Essa segunda Análise Fatorial apresentou um KMO $=0,892$ e teste de esfericidade de Bartlett $=2287,062 \mathrm{com}$ significância $=0,000$. Os fatores identificados quanto aos Valores Profissionais foram: Fator 1 - Capacidade e Qualificação; Fator 2 - Competência em Sala de Aula; Fator 3 - Relacionamento; e Fator 4 - Experiência Extra-acadêmica.

A confiabilidade das medidas foi atestada pelos índices do Alfa de Cronbach dos quatro fatores a seguir: Fator 1 - Capacidade e Qualificação (alfa de 0,89); Fator 2 - Competência em Sala de Aula (alfa de 0,88); Fator 3 - Relacionamento (alfa de 0,75); e Fator 4 - Experiência Extra-acadêmica (alfa de 0,67). Esse último fator apresentou um alfa inferior a 0,70 ; todavia, dado o caráter exploratório do estudo, os pesquisadores optaram por manter o fator. Os resultados dessas análises constam na Tabela 2 a seguir. 


\section{Tabela 2: Análise Fatorial Rotacionada para Valores Profissionais dos Docentes}

\begin{tabular}{l|c|c|c|c}
\hline \multicolumn{1}{c|}{ Variáveis } & Fator 1 & Fator 2 & Fator 3 & Fator 4 \\
\hline Curso de doutorado & 0,803 & & & \\
\hline Pontuação no Qualis & 0,782 & & & \\
\hline Possuir currículo Lattes & 0,741 & & & \\
\hline Participação em grupos de pesquisa do CNPq & 0,733 & & & \\
\hline Curso de mestrado & 0,689 & & & \\
\hline Publicação de artigos científicos & 0,689 & & & \\
\hline Curso de pós-doutorado & 0,725 & & & \\
\hline Participação em congressos e seminários & 0,561 & & & \\
\hline Dedicação exclusiva do professor & 0,578 & & & \\
\hline Capacidade técnica para orientaçóes & 0,452 & & & \\
\hline Capacidade para unir teoria e prática & & 0,815 & & \\
\hline Didática em sala de aula & & 0,772 & & \\
\hline Dedicação e entusiasmo do professor & & 0,723 & & \\
\hline Relacionamento com os alunos & & 0,678 & & \\
\hline Criatividade do professor & & 0,656 & & \\
\hline Leitura de periódicos específicos da área & & 0,529 & & \\
\hline Contato com outros acadêmicos & & & 0,653 & \\
\hline Relacionamento com a coordenação do curso & & & 0,671 & \\
\hline Interesse por orientações & & & 0,548 & \\
\hline Relacionamento com outros professores & & & 0,653 & \\
\hline Ocupação extra-acadêmica & & & & 0,806 \\
\hline Experiência profissional anterior extra-acadêmica & & & & 0,695 \\
\hline Variância explicada & $23,24 \%$ & $19,16 \%$ & $12,40 \%$ & $8,10 \%$ \\
\hline Variância acumulada & $23,24 \%$ & $42,40 \%$ & $54,80 \%$ & $62,90 \%$ \\
\hline Alfa de Cronbach & 0,893 & 0,878 & 0,752 & 0,672 \\
\hline Fon & & & &
\end{tabular}

Fonte: dados primários da pesquisa.

Complementando a validação das escalas foram seguidos outros procedimentos. É preciso observar que um instrumento só é valido, se ele mede efetivamente aquilo que se propõe mensurar (Guilford, 1954; Nunnally, 1967). Na literatura especializada as formas mais comuns de se atestar a validade de uma escala são: (1) validade de conteúdo (aparente ou de face) que utiliza a opinião de especialistas quanto ao conteúdo das escalas; e (2) validade de construto (de conceito ou fatorial), que ocorre por meio da análise da convergência dos indicadores em um mesmo fator e discriminação entre indicadores de diferentes fatores (Guilford, 1954; Nunnally, 1967).

A validação de face das medidas utilizadas nesse levantamento foi realizada por professores mestres, doutores e pós-doutores da área de administração, economia e educação, que não estiveram envolvidos na realização da pesquisa. Nesse processo ocorreu o exame dos fatores e indicadores das escalas desenvolvidas no estudo. Dois pós-doutores e um doutor em economia, dois doutores e um mestre em administração, e um mestre em educação atestaram a validade de conteúdo de acordo com a denominação dos fatores (Guilford, 1954). 
Além da análise de dimensionalidade com a AFE das escalas a validação de construto foi realizada por meio do exame de validade convergente e discriminante. De acordo com Nunnally (1967) é recomendável que se faça uso de amostras diferentes no processo de validação das medidas. Todavia as limitações de recursos e também o tamanho da amostra não possibilitaram duas ou mais coletas de dados de forma separada. Para tanto, fez-se uso da Análise Fatorial Exploratória [AFE], dividindo-se aleatoriamente a amostra em duas partes. O primeiro grupo, chamado de grupo teste foi formado por 94 casos, enquanto o grupo de validação foi composto pelos 120 casos restantes da amostra total. Observando o resultado da Análise Fatorial Exploratória dos dois grupos, foi considerada satisfatória a estabilidade dos indicadores de cada dimensão dos construtos em exame. O construto Adequação das IES apresentou estabilidade de todos os indicadores nos fatores esperados, de acordo com a Análise Fatorial do grupo teste. Apenas dois indicadores do construto Perfil de Docente não alcançaram estabilidade nas soluções fatoriais do grupo teste $\mathrm{e}$ grupo validação: (1) Interesse por orientações, e (2) Leitura de periódicos específicos da área. Tal achado reforça a necessidade de replicação da escala em estudos futuros para uma possível purificação das medidas (Nunnally, 1967). No presente estudo optou-se por manter os indicadores das dimensões encontradas na solução da Análise Fatorial com a amostra total.

Para examinar a validade convergente e discriminante, Kidder (1987) propõe a utilização da matriz multitraços-multimétodos [MTMM], que apresenta uma tabela de correlações entre construtos e formas de mensuração. Todavia Bagozzi e Phillips (1991) afirmam que esse processo de validação com a MTMM não proporciona resultados confiáveis e sugerem uma abordagem de validação de construto com a Análise Fatorial Confirmatória [AFC]. Entretanto, como é recomendável que a AFC não seja aplicada na mesma amostra de casos em que foi aplicada a AFE, também foi descartada essa opção. A partir desses apontamentos pareceu mais adequado, nesse primeiro estudo, a simples verificação da matriz de correlações entre todos os indicadores. Após a aplicação do teste de correlação bivariada de Pearson foi possível perceber que todos os indicadores de cada dimensão ou subconstruto estão bastante correlacionados entre si, com coeficientes de correlação acima de 0,50 ( $p$-value < 0,05), o que sugere convergência dos indicadores em um mesmo fator. Alguns dos indicadores apareceram correlacionados com indicadores de outros fatores; mas, quando as correlações foram estatisticamente significativas, o coeficiente de correlação foi relativamente baixo, em comparação às correlações com os indicadores da sua própria dimensão, o que ofereceu suporte à validade discriminante das escalas. De qualquer forma, é preciso ressaltar a necessidade de análises posteriores das escalas. 
Posteriormente, dado o objetivo do presente estudo, que é verificar a existência ou não de padrões estruturados de cognição, a técnica estatística mais recomendada, após os procedimentos de validação das escalas, foi a Análise de Cluster (Análise de Conglomerados). Para os fatores do construto Adequação das IES não foram encontrados grupos com diferenças estatisticamente significativas na ANOVA, depois da Análise de Cluster. Para a Análise de Cluster dos fatores do Perfil de Docente, foram encontrados 3 grupos bastante homogêneos internamente e heterogêneos dos demais grupos da taxonomia: classificação empírica ao invés de uma classificação teórica.

O primeiro procedimento para a verificação da existência desses grupos foi a realização de uma análise de cluster hierárquica, com o método de Ward e distância euclidiana ao quadrado (Hair et al., 1995). A partir da observação do dendograma (representação gráfica dos clusters), que sugeriu a existência de três grupos mais gerais, também foram identificados 6 respondentes que figuraram como outliers na amostra; por isso foram extraídos do conjunto de observações para as análises posteriores.

Para a verificação das diferenças estatisticamente significativas entre os grupos para os fatores do construto Perfil de Docente, foi realizada uma Análise de Variância das médias (ANOVA) e o Teste Post hoc de Tukey (teste de comparações múltiplas). AANOVA foi significativa ao $p$-value $<0,000$ nos quatro fatores encontrados. No teste de comparação das médias foram encontradas diferenças significativas ( $p$-value $<0,000)$ entre todos os fatores em pelo menos 2 grupos, conforme indicado na Tabela 3.

Tabela 3: Médias e Teste Post hoc de Tukey para Importância

\begin{tabular}{l|c|c|c}
\hline & Grupo 1 = 46 & Grupo 2 = 104 & Grupo 3= 57 \\
\hline Capacidade e Qualificação & 3,92 & 4,20 & 3,11 \\
\hline Competência em Sala & $4,54 \mathbf{a}$ & 4,76 & 4,49 a \\
\hline Relacionamento & $4,12 \mathbf{a}$ & 4,47 & $3,96 \mathbf{a}$ \\
\hline Experiência & 3,08 & $4,41 \mathbf{a}$ & $4,37 \mathbf{a}$ \\
\hline
\end{tabular}

a: sem diferença significativa.

Fonte: dados primários da pesquisa.

\section{Discussão dos Resultados}

Interpretando os dados a partir das análises, foi possível observar a bidimensionalidade do construto Adequação das IES na percepção dos docentes do curso de administração e a composição dos valores relacionados ao Perfil de Docente em outros quatro fatores. 
A Adequação das IES parece ser separada em dois fatores principais, na percepção dos docentes pesquisados: o Apoio da Instituição e a Estrutura. É relevante notar os indicadores que compõem o primeiro fator do construto Adequação das IES. De forma geral, para se garantir a qualidade do ensino em administração seria indispensável o apoio das instituições na qualificação desses docentes. Esse apoio parece residir no provimento de recursos econômicos e temporais para cursos de qualificação, para atividades extracurriculares e para a participação em eventos. Entretanto o apoio das IES não deveria restringir-se ao provimento desses recursos, o incentivo de natureza social, ou como é evidenciado na Análise Fatorial, o apoio moral para a realização de pesquisas e publicações também está correlacionado com os outros indicadores da dimensão Apoio Institucional.

A segunda dimensão do fator Adequação das IES reside mais especificamente na Estrutura. Nesse ponto parece existir um conjunto reduzido de critérios pelo qual se dá a avaliação dos docentes. Esse fator foi composto por apenas três indicadores: (i) equipamentos de apoio; (ii) instalações físicas; e (iii) bibliotecas. Nesse sentido é possível inferir que, aos docentes que participaram da pesquisa, bastaria equipamento de apoio às aulas, como os recursos audiovisuais, salas e biblioteca em condições adequadas para se garantir a qualidade do ensino no que concerne à Adequação das IES na dimensão Estrutura.

O consenso a respeito da necessidade de Apoio Institucional e adequação da Estrutura das IES é um fator que pode estar altamente institucionalizado entre os professores pesquisados. Como foi apresentado anteriormente, não foram encontradas diferenças estatisticamente significativas, a partir da ANOVA, na valoração desses critérios entre os diferentes grupos de docentes que emergiram da análise de Cluster para esses dois fatores. A julgar pelos docentes envolvidos no presente estudo, há indícios de alto grau de sedimentação de tais pressupostos. Nesse sentido, as crenças e valores relacionados ao Apoio Institucional e à qualidade das características que representam a Estrutura das IES dos cursos de administração em Curitiba parecem figurar como pressupostos bastante racionalizados no entendimento das condições de trabalho desses docentes (DiMaggio \& Powell, 1983; Meyer \& Rowan, 1977).

A racionalização e o grau de sedimentação aparente desses padrões cognitivos que dão os contornos de uma das facetas do mecanismo isomórfico normativo teoricamente resulta de um processo histórico e dialético da formação de hábitos, do discurso da importância dos fatores tidos como cruciais para o desempenho das funções atreladas à profissão, que posteriormente foram incorporadas a um corpo de rotinas do grupo, por meio das quais alcançaram então, status de ações tomadas como certas (Berger \& Luckmann, 1998). Logo, diante do grau de 
institucionalização de tais pressupostos (crenças e valores) e o decorrente grau de legitimidade de tal padrão compartilhado de cognição seria razoável presumir a tendência à continuidade desses padrões institucionais, pelo menos para o grupo de atores sociais dessa categoria de trabalho, pois a adesão a padrões institucionais e o compartilhamento de valores racionalizados na sociedade tendem a premiar com a legitimidade os atores sociais imersos nessa mesma arena de natureza normativa (DiMaggio \& Powell, 1983; Meyer \& Rowan, 1977; Scott, 2001).

Por outro lado, quando se discutem as características mais importantes do Perfil de Docente desejado para o curso de administração, existe um número bem maior de variáveis a considerar. A fase qualitativa desse estudo revelou 22 características principais do professor para se garantir a qualidade do ensino. Quando esse conjunto de indicadores foi submetido a uma Análise Fatorial para redução das variáveis a poucas dimensões restaram quatro fatores principais. De forma geral, os docentes pesquisados parecem valorizar, ainda que em graus variados, a Capacidade e Qualificação, a Competência em Sala de Aula, o Relacionamento, e a Experiência Extra-acadêmica dos professores.

O fator Capacidade e Qualificação (Fator 1) revela a valorização de certificações; por exemplo, títulos de mestre e doutor, participação em grupos de pesquisa, publicações científicas, participações em congresso e capacidade técnica do professor. Como mostra o resultado da Análise Fatorial, em razão de as variáveis estarem correlacionadas, os docentes parecem avaliar, em sua maioria, a capacidade técnica do professor, a partir de critérios de certificação que atestam a formação profissional do docente. De acordo com Scott (2001), a certificação dá suporte e opera como meio de legitimação para o exercício de atividades em contextos institucionais específicos. No caso dos docentes pesquisados, isso parece mais verdade em função da busca por legitimidade dos profissionais junto às IES, que decorre da necessidade de suporte, aceitação e também certificação das IES pelos órgãos do Estado que regulamentam a educação.

O fator Competência em Sala de Aula (Fator 2) se assenta principalmente na didática, entusiasmo, dedicação e capacidade do professor em unir teoria e prática. Nesse sentido, talvez possa existir uma associação positiva entre capacidade de unir teoria e prática e o entusiasmo e dedicação do professor, pelo menos no que tange à interpretação dos docentes. Os professores pesquisados podem estar relacionando a dedicação e entusiasmo em sala de aula com a sua capacidade de unir teoria e prática. As variáveis que compõem esse segundo fator estão positivamente relacionadas e apresentam variação sistemática, convergindo num mesmo fator. Tal assertiva talvez possa ser explicada em função da dedicação expressa na melhor preparação das aulas, explanações acerca de exemplos e trabalhos em sala, que estão mais relacionadas e próximas ao mundo de verdade, 
como defendem muitos alunos e docentes que atribuem status de curso estritamente teórico à área de administração. Assim como ocorre com a valorização da certificação, a valorização da competência em sala está intimamente relacionada tanto a determinações preestabelecidas por regras quanto a padrões esperados de comportamentos e pressupostos, o que ressalta a dificuldade de se separar, mesmo que somente para fins analíticos, que valores estão mais proximamente atrelados às dimensões regulativa, normativa ou cognitivo-cultural, propostas por $S \operatorname{cott}(2001)$.

O fator Relacionamento (Fator 3) evidencia a importância dada à questão de o docente construir e manter relacionamentos, além dos limites da sala de aula. Nesse terceiro fator estão relacionadas as seguintes variáveis: (i) contatos com outros acadêmicos; (ii) relacionamento com a coordenação do curso; (iii) relacionamento com outros professores; e (iv) interesse por orientações. Essa dimensão das características profissionais valorizadas em um docente, na ótica dos próprios professores, pode ser um reflexo da importância dos contatos nesse meio profissional. Não é surpresa a identificação dessa dimensão, pois o capital social dos docentes - sua rede de relacionamentos sociais - é origem de várias oportunidades e informações, bem como da construção de legitimidade e obtenção de outros recursos. Como afirmam DiMaggio e Powell (1983) as redes de profissionais, mesmo que informais, possibilitam a rápida difusão de novas práticas e métodos de trabalho e o acesso a eles.

O fator Experiência Extra-acadêmica (Fator 4) pode estar relacionado à valorização da ocupação profissional dos docentes fora da sala de aula. Os dois indicadores dessa quarta dimensão do perfil profissional de docente esperado são: (i) ocupação extra-acadêmica; e (ii) experiência profissional anterior extraacadêmica. Respectivamente, essas variáveis remetem à valorização por professores que exercem cargos não relacionados à docência atualmente ou já exerceram esses cargos antes da atividade de docência. Esse fator coloca em evidência a velha preocupação com a prática. É comum a existência de um discurso, na maioria das IES, que valoriza a atuação prática dos docentes dentro da realidade do mercado de trabalho. Esse parece ser um valor já institucionalizado em algum grau nessa categoria profissional e no campo organizacional do ensino superior. Todavia percebe-se aqui a presença de crenças e valores que podem figurar até como contradições institucionais em relação aos fatores anteriores. Tais contradições podem pressionar num sentido diametralmente oposto às crenças e valores dos outros fatores da pesquisa e vir a contribuir para algumas mudanças institucionais (Berger \& Luckmann, 1998; Scott, 2001).

Deve-se atentar para o fato de que a identificação dessas diferentes dimensões implica não considerar, de maneira sumária e única, um ou outro fator que possa 
expressar os valores dos docentes pesquisados. Em primeiro lugar, essas características refletem somente uma pequena parte dos valores profissionais dos docentes pesquisados. Em complemento, é bastante razoável admitir que alguns docentes possam apresentar maior valorização de algumas dessas dimensões do perfil profissional, enquanto outros docentes valorizam outras dimensões. Em face desse argumento em que se baseia todo o presente estudo, discutem-se agora os achados empíricos da Análise de Cluster dos fatores do Perfil de Docente, por meio da qual foram encontrados 3 grupos de docentes (sugeridos pelo dendograma).

Como já foi exposto na Tabela 3, a amostra final da pesquisa resultou em três grupos diferenciados no que concerne à importância ou, como é tratada aqui, à valorização das características profissionais do docente do curso de administração. A Competência em Sala foi a característica mais valorizada pelos três grupos. Essa dimensão do Perfil Profissional foi o fator que apresentou as diferenças menos acentuadas. Para o restante das variáveis foram identificadas diferenças mais significativas.

O primeiro cluster consiste em um grupo de apenas 46 docentes $(22,22 \%$ da amostra). Esse grupo é o que menos valoriza a Experiência Extra-acadêmica. Ainda na comparação com os outros dois clusters, esse grupo valoriza de forma moderada o fator Capacidade e Qualificação. Quanto à Competência em Sala e Relacionamento, esse grupo valoriza menos esses fatores somente em comparação ao grupo 2. O segundo cluster (50,25\% da amostra), maior grupo da pesquisa $(n=104)$ é o grupo que valoriza mais intensamente todos os quatro fatores relacionados às características do docente, e se assemelha estatisticamente somente ao terceiro cluster na valorização da Experiência Extra-acadêmica. $\mathrm{O}$ terceiro grupo $(n=57)(27,53 \%$ da amostra) é o grupo de docentes que menos valoriza a Capacidade e Qualificação. Esse grupo também valoriza na mesma intensidade que o grupo 1 os fatores Competência em Sala e Relacionamento, mas valoriza em nível inferior esses fatores na comparação com o grupo 2.

Na seqüência, em face da tentativa de perfilar mais acuradamente esses três grupos, foi realizado o teste Qui Quadrado $\left(\chi^{2}\right)$ (Spiegel, 1988; Triola, 1999) para o nível de formação dos pesquisados, porém não foi encontrada diferença estatisticamente significativa na proporção dos docentes por nível de qualificação, considerando um $p$-value $<0,05$ (mestrandos foram incluídos na categoria mestres e doutorandos na categoria doutores).

De forma geral, esses três grupos parecem ter como parte de um ideário de escola aspirar a três perfis mais gerais e desejados de docentes nos cursos de administração. Esses perfis esperados de docentes foram denominados aqui, a partir de três padrões estruturados (institucionalizados) de ideário de professor: o 
Docente Com Bom Relacionamento e Presença em Sala de Aula; o Docente Bem Qualificado; e o Docente Com Maior Experiência Profissional.

1. Docente Com Bom Relacionamento e Presença em Sala de Aula: esse cluster representa apenas $22,22 \%$ da amostra $(n=46)$. Os fatores mais valorizados por esse grupo e que melhor o diferenciam dos demais parecem residir na importância dada à Competência em Sala de Aula e ao Relacionamento. Esse grupo é o que menos valoriza a Experiência Extra-acadêmica na comparação com os outros clusters. Quanto à Capacidade e Qualificação tem uma média de importância moderada.

2. Docente Bem Qualificado: o segundo grupo identificado na Análise de Cluster é composto por $50,25 \%$ da amostra. É o maior cluster da pesquisa $(n=104)$ e é o grupo que valoriza mais intensamente todos os quatro fatores relacionados às características profissionais do docente. Esse grupo não se diferencia estatisticamente somente na valorização da Experiência Extra-acadêmica na comparação com o terceiro cluster.

3. Docente Com Maior Experiência Profissional: o terceiro cluster representa $27,53 \%$ da amostra $(n=57)$, e é o grupo que menos valoriza a Capacidade e Qualificação do docente. Esse cluster valoriza a Experiência Extraacadêmica tanto quanto o cluster 2; entretanto apresenta menor valorização da Competência em Sala de Aula e do Relacionamento, comparativamente a esse mesmo grupo.

\section{Considerações Finais}

Como se procurou estabelecer no decorrer do artigo, a proposta no presente estudo foi a de tornar mais claro o conjunto de fatores que dão forma às aspirações, ou ideário de escola na ótica dos docentes. A pesquisa foi levada a cabo à luz da observação do grau de importância, atribuído pelos docentes aos seus critérios de avaliação, utilizados no julgamento da qualidade do ensino superior no curso de administração na cidade de Curitiba, PR.

Em complemento, buscou-se identificar a presença ou não de padrões estruturados de cognição entre os docentes pesquisados, com o objetivo de verificar a pura subjetividade de cada docente na sua valoração de determinadas características da escola ideal, ou a existência de padrões intersubjetivamente compartilhados no que se refere à sua maneira de interpretar a realidade (Berger \& Luckmann, 1998; Scott, 2001). De toda forma, convém, antes de quaisquer apontamentos mais gerais, evidenciar as limitações que estiveram no entorno dessa pesquisa. 
A despeito de que os achados empíricos fazem referência a uma amostra suficientemente ampla de professores pesquisados, certas limitações do estudo devem ser destacadas. A amostra final da pesquisa se configura em uma amostra por adesão e não em uma amostra probabilística. Decorre daí que as conclusões e inferências realizadas a partir dos resultados da pesquisa devem ser olhadas sempre com cautela.

Uma segunda limitação da pesquisa reside na forma de mensuração utilizada no estudo. As opções e delineamentos de pesquisa sempre carregam em si relações custo-benefício que exigem exercícios de trade-offs por parte do pesquisador. Aqui se primou pela amplitude da análise em detrimento da profundidade na investigação da essência do fenômeno da valoração de alguns critérios de qualidade por parte dos docentes. Deve-se ter em mente que os critérios de qualidade apontados aqui mais refletem os valores dos pesquisados do que mostram os valores em si mesmos. Na pesquisa foram utilizados questionários estruturados para a coleta dos dados e não a tradicional observação ou realização de entrevistas para a captura dos significados que envolvem os valores de indivíduos imersos em sistemas sociais de espectro mais amplo.

A terceira limitação da pesquisa reside na natureza incipiente do assunto cognição estruturada na ótica da Teoria Institucional e da Abordagem Cognitiva dos estudos organizacionais. Todavia a fragilidade dos achados de uma pesquisa de objetivo eminentemente exploratório traz em si também um leque de oportunidades de pesquisas sobre o assunto e outros construtos relacionados.

No que concerne aos resultados da pesquisa devem ser salientados os fatores identificados no estudo com os docentes do curso de Administração. Os fatores Apoio Institucional e Estrutura revelam as duas principais dimensões de avaliação no que se refere à Adequação das IES privadas como um todo. É importante reafirmar que não foram encontradas diferenças significativas nas médias entre grupos para essas dimensões, ou seja, os docentes pesquisados parecem não valorizar de forma diferenciada tais fatores. Uma provável explicação para tal constatação talvez seja a homogeneidade nas estruturas das IES na capital paranaense. É bastante aparente a crescente falta de diferenciação entre as escolas de administração de Curitiba. Outra explicação poderia residir ainda na pura falta de valorização desses fatores. Nesse sentido, os docentes poderiam estar cientes do ínfimo papel e da reduzida influência desses fatores na qualidade de ensino dos cursos pesquisados. Por outro lado, a não diferenciação nas médias entre grupos para o fator Apoio Institucional deveria ser alvo de pesquisas futuras para maiores esclarecimentos.

A maior diferenciação entre grupos de docentes se estabeleceu a partir do nível de valoração para as características do perfil profissional do professor de 
administração. A valoração desses atributos se deu a partir de quatro fatores principais: (i) Capacidade e Qualificação; (ii) Competência em Sala de Aula; (iii) Relacionamento; e (iv) Experiência Extra-acadêmica.

A partir do nível de importância, ou valoração, dos quatro fatores relacionados às características do perfil profissional do docente foram encontrados três clusters entre os pesquisados. Cada grupo sustenta um ideário de docente relativamente heterogêneo dos demais grupos identificados no decorrer da pesquisa.

O primeiro grupo tem como ideal de profissional o Docente Com Bom Relacionamento e Presença em Sala de Aula. O segundo grupo entende como professor capaz de assegurar a qualidade no ensino o Docente Bem Qualificado. O terceiro grupo percebe o Docente Com Maior Experiência Profissional como o profissional ideal.

Algumas primeiras implicações desses padrões estruturados de cognição (Machado-da-Silva et al., 2005; Selznick, 1996) dizem respeito à realidade da própria categoria profissional. Como admitem os institucionalistas (DiMaggio \& Powell, 1983; Machado-da-Silva et al., 1999), o mecanismo isomórfico normativo, que tende a agir como instrumento de homogeneização das práticas e atividades das organizações (neste caso organizações de ensino) tem sua origem primariamente na profissionalização, interpretada por DiMaggio e Powell (1983, p. 152), como "a luta coletiva dos membros de uma ocupação para definir as condições e métodos de sua atividade [...] e para estabelecer uma base cognitiva e de legitimação para sua autonomia ocupacional”. Entretanto, como apontam os resultados reportados aqui, ao considerar essa classe de profissionais, o fenômeno de definição e difusão de condições e métodos de atividades de trabalho não pode ser considerado de maneira monolítica. Há de se tomar em consideração a existência de padrões estruturados de cognição (Selznick, 1996).

Sobretudo, não basta apenas considerar a presença de tais padrões cognitivos, mas também entender a relação entre esses padrões e diferentes estruturas institucionais que operam em variados níveis e partes do contexto ambiental. Tal assertiva coloca em evidência a mútua e contínua interação de um contexto institucional fragmentado com padrões institucionalizados de cognição e práticas sociais diferenciadas (Giddens, 1989; Machado-da-Silva et al., 1999; Machadoda-Silva et al., 2005).

A maior importância desses padrões estruturados de cognição reside na noção do binômio interpretação-ação. É bastante razoável inferir que os indivíduos agem de forma consistente em grande medida com suas crenças e valores. E, portanto, observar os elementos de valoração desses profissionais equivale a observar as bases de interpretação e da forma de se aperfeiçoar, de se relacionar, de ensinar, 
de avaliar alunos e de se ver como professor. Nesse sentido, torna-se muito clara a dinâmica de interdependência e reciprocidade das crenças e valores desses profissionais com as regras, normas e pressupostos que dão vida aos padrões sociais e contexto em que estão circunscritas as relações de ensino e aprendizagem.

E, como sugerem os resultados, ao contrário dos argumentos iniciais de DiMaggio e Powell (1983), o mecanismo isomórfico normativo pode refletir-se de forma muito mais fragmentada, por meio de diferentes instituições com variados níveis de institucionalização, em função de diferentes padrões de interpretação de algumas dimensões das condições e métodos de trabalho de determinada categoria profissional.

Logo, não é demais imaginar que é justamente essa fragmentação da base cognitiva e de legitimação da autonomia ocupacional (DiMaggio \& Powell, 1983) que dá vazão a diferentes instituições que concorrem na homogeneização das práticas desses atores sociais. Em adição, é preciso salientar a lógica de recursividade que permeia essa mútua e contínua interação de padrões cognitivos e contradições institucionais (Giddens, 1989). Tanto esses padrões cognitivos dão forma e garantem a estabilidade de algumas instituições, quanto essas instituições servem de plataforma para a estruturação dos esquemas interpretativos e a ação de atores sociais que pertencem a grupos distintos, no que tange a sua forma de interpretar o que seja qualidade no ensino superior para o curso em exame.

Em resumo pôde-se constatar que, na ótica dos professores, as diferenças de um ideário de escola parecem residir muito mais nas características do perfil profissional dos docentes do que na estrutura da escola em si. Em complemento, deve-se considerar a diversidade nos ideais de profissional entre os pesquisados e talvez questionar: Existem níveis mais adequados de diferenciação entre esses grupos? Deveriam esses docentes formar um único grupo na sua forma de entender o docente mais recomendado para se garantir a qualidade no ensino de administração? Qual o limite de tal diversidade? Como fica a questão da qualidade do ensino nos cursos de administração, em face dessa configuração mais plural e diversificada na forma dos docentes em entender o que é qualidade?

De forma geral, os resultados da pesquisa sugerem a ausência de uma única e tão somente pura subjetividade dos docentes (Berger \& Luckmann, 1998; Scott, 2001); tampouco sugerem a completa intersubjetividade de valores entre todos os docentes. Na verdade, oferece indícios da existência de limites entre padrões estruturados de cognição (Cochia \& Machado-da-Silva, 2004), que podem diferenciar-se em razão do contexto ambiental de referência, grupos de referência, história de vida e até mesmo da cultura nas organizações em que esses docentes trabalham, ou das redes de relacionamentos de que esses atores sociais fazem 
parte (DiMaggio \& Powell, 1983; Granovetter, 1985; Machado-da-Silva et al., 1999; Machado-da-Silva et al., 2005; Selznick, 1996).

Essas considerações anteriores fazem pensar nos apontamentos de Meyer e Rowan (1977) em que os autores defendem que normas racionalizadas não operam simplesmente como valores gerais, mas, que essas normas ou padrões esperados de comportamento se assentam em regras, entendimentos e significados muito mais poderosos e específicos que estão atrelados a uma maior diversidade de estruturas sociais institucionalizadas. Como atestam Friedland e Alford (1991) muitas instituições presentes na atualidade são potencialmente contraditórias e colocam à disposição dos atores sociais múltiplas lógicas de ação. A noção de uma multiplicidade de lógicas de ação pode ser adequada para o exercício de exploração das origens de diferentes padrões institucionalizados de cognição. Em complemento, esse raciocínio abre espaço para a incorporação da dinâmica entre estabilidade e mudança em diferentes arranjos institucionais. Como fica aparente nos resultados do presente estudo se pôde identificar um reflexo de pelo menos três fontes principais de isomorfismo que concorrem na homogeneização das práticas e atividades dos docentes que fizeram parte da pesquisa.

No plano empírico essa diversidade de padrões cognitivos que mantêm vivas instituições potencialmente contraditórias traz tanto vantagens quanto desvantagens de uma realidade em constante mudança. Por um lado, essas contradições institucionais podem figurar como oportunidades de inovação; por outro lado, elas representam uma falta de homogeneidade e desconexão das estruturas formais dos cursos de Administração com as atividades que realmente são desempenhadas pelos docentes das Instituições de Ensino Superior.

Como os resultados do estudo permitem especular, IES congregam sob uma única estrutura formal docentes com interpretações diferenciadas do que seja qualidade para um curso de Administração. Decorre daí que o desencaixe (decoupling) entre estruturas organizacionais que aparentemente buscam sempre a eficiência e as atividades efetivas de seus docentes (Meyer \& Rowan, 1977), também poderia ser identificado de forma mais complexa. Considerando esse argumento, pode ser que exista um número maior de especificidades e diferenças no entorno da distância entre as atividades desempenhadas realmente nas IES daquelas previstas em suas estruturas formais (Meyer \& Rowan, 1977). Dentro desse raciocínio a simples classificação de sistemas e estruturas em estado de decoupling, loosely coupling e tightly coupling deveria ser repensada à luz de um ambiente externo e também interno mais complexo e fragmentado (Orton \& Weick, 1990).

Em face da fragmentação interna das atividades e práticas em comparação das estruturas formais das organizações, Orton e Weick (1990) apresentam 
mecanismos de compensação para tal diversidade de ações e formas de pensar, tanto em relação umas com as outras quanto em relação às práticas sustentadas na estrutura formal. Nesse caso, o decoupling é um fenômeno de ordem organizacional que deve ser revertido. Esses autores discutem liderança, concentração de esforços e valores compartilhados como possíveis redutores da fragmentação nas ações e formas de interpretação de atores sociais presentes em um sistema organizacional.

Fundamentalmente, esses mecanismos podem operar num sentido de coesão e de uniformidade na estruturação de um padrão institucionalizado de cognição mais homogêneo. Em conjunto, a liderança, a concentração de esforços e a congruência de valores, parecem depender substancialmente tanto das regras, normas e pressupostos de atores quanto da estrutura de uma arena social que dê vazão à sua formação (Granovetter, 1985; Orton \& Weick, 1990).

Daí pode-se argumentar em favor de futuras pesquisas que explorem a relação entre padrões estruturados de cognição, redes sociais e a lógica de mudança e estabilidade, a partir da observação de contradições institucionais (Friedland \& Alford, 1991). O exame da relação e mútua influência entre redes sociais e padrões cognitivos e comportamentais pode contribuir substancialmente na compreensão da interdependência desses elementos em movimentos que operam ora em uma lógica de persistência, ora em uma lógica de mudança (DiMaggio \& Powell, 1983, 1991; Granovetter, 1985; Orton \& Weick, 1990; Scott, 2001). Nesse sentido, recomenda-se a consideração do fenômeno do embeddedness, a partir de duas das suas facetas mais gerais, o embeddedness institucional e o embeddedness estrutural (Dacin, Ventresca, \& Beal, 1999; Uzzi, 1996, 1997). Dessa forma, evita-se a submissão a certo grau de indeterminação teórica que o conceito sofre no clássico artigo de Granovetter (1985). A imersão institucional das organizações deve ser compreendida à luz de regras, normas e crenças e valores dispersos em um contexto institucional, enquanto a imersão estrutural dos relacionamentos interorganizacionais pode ser entendida nos termos da Análise estrutural de redes (Uzzi, 1996, 1997).

Por fim, percebe-se que existem diferenças entre docentes na forma de interpretar a realidade do ensino em administração, ou seja, foi possível constatar empiricamente a presença de padrões institucionalizados de cognição entre os envolvidos no estudo. Resta saber quais são os fatores responsáveis por essas formas estruturadas de interpretação. Mas esse será outro passo na tarefa de descobrir quem somos nós [sic], enquanto educadores que atuam nessa área de ensino.

\section{Artigo recebido em 26.05.2006. Aprovado em 21.12.2006.}




\section{Referências Bibliográficas}

Abell, P. (1995).

The new institutionalism and rational choice theory. In W. R. Scott \& S. Christensen (Eds.). The institutional construction of organizations: international and longitudinal studies (pp. 3-14). Thousand Oaks: Sage.

Babbie, E. R. (1998).

The practice of social research. Califórnia: Wadsworth Publishing Company.

Babbie, E. R. (2001). Métodos de pesquisa de survey. Belo Horizonte: Editora UFMG.

Bagozzi, R. P.,

Yi, Y., \&

Phillips, L. W. (1991).

Assessing construct validity in organizational research. Administrative Science Quarterly, 36(3), 421-458.

Bartel, C. A., \&

Saavedra, R. (2000).

The collective construction of work group moods. Administrative Science Quarterly, 45(2), 197-231.

Bartunek, J. M. (1984).

Changing interpretative schemes and organizational restructuring: the example of a religious order. Administrative Science Quarterly, 29(3), 355-372.

Berger, P. L., \&

Luckmann, T. (1998).

A construção social da realidade. Petrópolis: Vozes.
Cochia, C. B. R., \&

Machado-da-Silva, C. L. (2004).

Ambiente, interpretação e estratégia em organizações paranaenses dos setores de vestuário e alimentos. Revista de Administração Contemporânea, 8(Edição Especial), 11-35.

Dacin, M. T.,

Ventresca, M. J., \&

Beal, B. D. (1999).

The embeddedness of organizations: dialogue and directions. Journal of Management, 25(3), 317-356.

Daft, R. L., \&

Weick, K. E. (1984).

Toward a model of organizations as interpretation systems. Academy of Management Review, 9(2), 284-295.

DiMaggio, P. J., \&

Powell, W. W. (1983).

The iron cage revisited: institutional isomorphism and collective rationality in organization fields. American Sociological Review, 48(2), 147-160.

DiMaggio, P. J., \&

Powell, W. W. (1991).

Introduction. In W. W. Powell \& P. J. DiMaggio (Eds.). The new institutionalism in organizational analysis (pp. 1-38). Chicago: The University of Chicago Press. 
Dukerich, J. M.,

Golden, B. R., \&

Shortell, S. M. (2002).

Beauty is in the eye of the beholder the impact of organizational identification, identity, and image on the cooperative behaviors of physicians. Administrative Science Quarterly, 47(3), 507-559.

Fahr, J. L.,

Earley, P. C., \&

Lin, S. C. (1997).

Impetus for action: a cultural analysis of justice and organizational citizenship behavior in chinese society. Administrative Science Quarterly, 42(2), 421-44.

Festinalli, R. S. (2005, setembro).

A formação de mestres em administração: por onde andamos? Anais do Encontro Nacional da Associação Nacional de PósGraduação e Pesquisa em Administração, Brasília, DF, Brasil, 29.

Friedland, R., \&

Alford, R. R. (1991).

Bringing society back in: symbols, practices, and institutional contradictions. In W. W. Powell \& P. J. DiMaggio (Eds.). The new institutionalism in organizational analysis (pp. 232-263). Chicago: The University of Chicago Press.

Giddens, A. (1989).

A constituição da sociedade. São Paulo: Martins Fontes.

Granovetter, M. (1985).

Economic action and social structure: the problem of embeddedness. American Journal of Sociology, 91(3), 481-510.
Greenwood, R., \&

Hinings, C. R. (1993).

Understanding strategic change: the contribution of archetypes. Academy of Management Journal, 36(5), 10521081.

Greenwood, R., \&

Hinings, C. R. (1996).

Understanding radical organizational change: bringing together the old and the new institutionalism. Academy of Management Review, 21(4), 10221054

Guarido, E. R., Filho, \&

Machado-da-Silva, C. L. (2001).

A influência de valores ambientais e organizacionais sobre a aprendizagem organizacional na indústria alimentícia paranaense. Revista de Administração Contemporânea, 5(2), 33-63.

Guilford, J. P. (1954).

Psychometric methods. New York: McGraw-Hill.

Hair, J. F.,

Anderson, R. E.,

Tatham, R. L., \&

Black, W. C. (1995).

Multivariate data analysis: with readings. New Jersey: Prentice-Hall, Inc.

Instituto Nacional de Estudos e Pesquisas Educacionais Anísio Teixeira. (2006).

Censo da educação superior: resultados e tendências. Recuperado em 20 março, 2006, de http:// www.inep.gov.br/superior/ censosuperior/resultados/ resultados_tendencias.htm 
Kerlinger, F. N. (2003).

Metodologia da pesquisa em ciências sociais. São Paulo: Editora Pedagógica e Universitária.

Kidder, L. H. (1987).

Métodos de pesquisa nas relações sociais: medidas na pesquisa social. São Paulo: EPU.

Machado-da-Silva, C. L. (2003).

Respostas estratégicas da administração e contabilidade ao sistema de avaliação da Capes. Organizações \& Sociedade, 10(28), 63-77.

Machado-da-Silva, C. L., \&

Fonseca, V. (1993, setembro).

Homogeneização e diversidade organizacional: uma visão integrativa. Anais do Encontro Nacional da Associação Nacional de PósGraduação e Pesquisa em Administração, Salvador, BA, Brasil, 17.

Machado-da-Silva, C. L.,

Fonseca, V., \&

Crubellate, J. M. (2005).

Estrutura, agência e interpretação: elementos para uma abordagem recursiva do processo de institucionalização. Revista de Administração Contemporânea, 9(Edição Especial), 09-39.

Machado-da-Silva, C. L.,

Fonseca, V., \&

Fernandes, B. H. R. (1999).

Mudança e estratégia nas organizações: perspectivas cognitiva e institucional. In M. M. F. Vieira \& L. M. B. Oliveira (Eds.). Administração contemporânea: perspectivas estratégicas (pp. 102-116). São Paulo: Atlas.
Machado-da-Silva, C. L., \&

Gonçalves, S. A. (1999).

Nota técnica: teoria institucional. In S. R. Clegg, C. Hardy, \& W. R. Nord (Eds.). Handbook de estudos organizacionais (pp. 220-226). São Paulo: Atlas.

Marconi, M. A., \&

Lakatos, E. M. (1990).

Técnicas de pesquisa: planejamento e execução de pesquisas, amostragens e técnicas de pesquisa, elaboração e interpretação de dados. São Paulo: Atlas.

Meyer, J. W., \&

Rowan, B. (1977).

Institutionalized organizations: formal structure as myth and ceremony. American Journal of Sociology, 83(2), 340-363.

Morosini, M. C. (1997).

Autonomia acadêmica, prática pedagógica e controle do conhecimento. In D. B. Leite \& M. C. Morosini (Eds.). Universidade futurante: produção do ensino e inovação (pp. 95-123). São Paulo: Papirus.

Motta, F. C. P. (1983).

A questão da formação do administrador. Revista de Administração de Empresas, 23(4), 53-55.

Neuman, L. W. (1997).

Social research methods: qualitative and quantitative approaches. Boston: Allyn \& Bacon.

Nunnally, J. C. (1967).

Psychometric theory. New York: McGraw-Hill. 
Oliveira, P. T., \&

Machado-da-Silva, C. L. (2001).

Características culturais nacionais em organizações do setor alimentício paranaense. Organizações \& Sociedade, 8(22), 27-48.

Orton, J. D., \&

Weick, K. E. (1990).

Loosely coupled systems: a reconceptualization. Academy of Management Review, 15(2), 203-223.

Polzer, J. T.,

Milton, L. P., \&

William, B. S., Jr. (2002).

Capitalizing on diversity: interpersonal congruence in small work groups. Administrative Science Quarterly, 47(2), 296-363.

Powell, W. W., \&

DiMaggio, P. J. (1991).

The new institutionalism in organizational analysis. Chicago: The University of Chicago Press.

Scott, W. R. (1992).

Organizations rational, natural, and open systems. New Jersey: Englewood Cliffs.

Scott, W. R. (1994).

Toward a theoretical synthesis. In W. R. Scott \& J. W. Meyer (Eds.). Intitutional environments and organizations. Thousand Oaks: Sage.

Scott, W. R. (1995).

Introduction: institutional theory and organizations. In W. R. Scott \& S. Christensen (Eds.). The institutional construction of organizations: international and longitudinal studies (pp. 11-23). Thousand Oaks: Sage.
Scott, W. R. (2001).

Institutions and organizations. Thousand Oaks: Sage.

Schumacker, R. E., \&

Lomax, R. G. (2004).

A beginner's guide to structural equation modeling. Mah-wah: Lawrence Erlbaum Associates Publishers.

Selznick, P. (1996).

Institutionalism "Old" and "New". Administrative Science Quarterly, 41(2), 270-277.

Simon, H. (1965).

Comportamento administrativo. Rio de Janeiro: FGV.

Spiegel, M. R. (1988).

Estatística. São Paulo: McGraw-Hill do Brasil.

Suchman, M. C. (1995).

Managing legitimacy: strategic and institutional approaches. Academy of Management Review, 20(3), 571-610.

Swaminathan, A. (1995).

The proliferation of specialist organizations in the american wine industry, 1941-1990. Administrative Science Quarterly, 40(4), 653-680.

Triola, M. F. (1999).

Introdução à estatística. Rio de Janeiro: LTC.

Uzzi, B. (1996).

The sources and consequences of embeddedness for the economic performance of organizations: the network effect. American Sociological Review, 61(4), 674-698. 
Uzzi, B. (1997).

Social structure and competition in interfirm networks: the paradox of embeddedness. Administrative Science Quarterly, 42(1), 35-67.

Vasconcelos, M. L. M. C. (1996). A formação do professor de terceiro grau. São Paulo: Pioneira.
Vergara, S. C. (1998).

Projetos e relatórios de pesquisa em administração. São Paulo: Atlas.

Westphal, J. D.,

Gulati, R., \&

Shortell, S. M. (1997).

Customization or conformity? An institutional and network perspective on the content and consequences of TQM adoption. Administrative Science Quarterly, 42(2), 366-394. 